\title{
Satisfação no trabalho: um estudo entre os funcionários dos hotéis de João Pessoa
}

\author{
Nelson Aleixo da Silva Junior ${ }^{1}$
}

\begin{abstract}
Resumo
Este estudo teve como objetivo verificar o nível de satisfação no trabalho, entre os funcionários dos hotéis de João Pessoa, tendo como referencial a teoria dos dois fatores de Frederick Herzberg. Dos 456 funcionários nos 14 hotéis com capacidade a partir de 70 leitos, foram estudados 69, provenientes dos hotéis da praia e dos hotéis centrais. Os dados foram coletados mediante um questionário e, em seguida, após a análise chegou-se à conclusão de que os funcionários estão satisfeitos no trabalho.

Palavras-chaves: Satisfação; insatisfação; motivação e trabalho.
\end{abstract}

Satisfaction in working: a study on the hotel employees in João Pessoa

\begin{abstract}
This study aims to verify the level of satisfaction at work among the hotel employees in João Pessoa and it based on Frederick Herzberg's two factory theory. It was taken a sample of 69 subjects out of 456 employees of the 14 beach and downtown hotels with a minimum capacity of 70 bedrooms. Those employees were given a questionnaire in order to get all the needed data. The conclusions drawn from the analysis was that the employees are satisfied with their jobs. Keywords: Satisfaction, motivation and work.
\end{abstract}

\section{Introdução}

A motivação, satisfação e insatisfação no trabalho têm sido alvo de estudos e pesquisas de teóricos das mais variadas correntes ao longo do século XX. Saber o que motiva, o que satisfaz o trabalhador, é descobrir o procedimento a ser adotado com relação a ele, para que melhore seu desempenho profissional e, por conseqüência, o desempenho organizacional. A teoria das organizações com as mais variadas escolas, é um exemplo claro a busca por uma melhor inserção do homem na organização.

Apesar de décadas de estudos, as opiniões são controversas, não existe uma opinião comum entre os pesquisadores sobre o que é e como ocorre a motivação, a satisfação e a insatisfação no trabalho. Archer (Bergamine \& Coda, 1990) define o motivo como sendo uma necessidade atuando sobre o intelecto, o que leva uma pessoa a agir. Partindo desse princípio, afirma que a motivação é uma tomada de direção para ação e originase de um motivo (necessidade). Neste contexto, o referido autor afirma que a satisfação ocorre com o atendimento ou a eliminação de uma necessidade. Na sua opinião, motivador e fator de satisfação são antítese. Ele alerta para a confusão que se faz entre fator de satisfação e necessidade, pois, é importante salientar que, o motivador é a necessidade e não o fator de satisfação da necessidade, assim sendo, "a motivação, portanto, nasce somente da necessidade humana e não daquelas coisas

${ }^{1}$ Endereço para correspondência:

R: Sabino Correia Neto, 117 - Mangabeira Prosind, João Pessoa- PB, 58056385.

E-mail: chinhim@zaz.com.br que satisfazem estas necessidades" (p.5).

Dentre as principais divergências existentes sobre este assunto, pode-se afirmar como principal a questão relacionada à natureza da motivação. Para alguns teóricos, os fatores extrínsecos ao indivíduo são motivadores, para outros não. Segundo Skinner (1972), a personalidade do homem pode ser modelada de acordo com uma programação previamente estabelecida, prevendo-se um controle rigoroso das variáveis exteriores. Assim sendo, a motivação nada mais é senão um esquema de ligação estímulo - resposta. $\mathrm{Na}$ opinião de Bergamine (Bergamine \& Coda, 1990) este tipo de teoria ilustra o comportamento reativo que leva ao movimento e não se pode chamar de motivação, pois uma pessoa não motiva outra, mas faz com que esta se movimente; assim, ela afirma (idem) que "o movimento é uma reação que surge e que perdura enquanto um reforçamento positivo está presente, e que semelhantemente desaparece quando tal tipo de recompensa não é oferecida, ou em lugar se oferece aos sujeitos reforçadores negativos, isto é, punições" (p.31). Continuando, cada pessoa caracteriza-se por um perfil motivacional próprio, sendo a motivação algo interno a cada ser humano, não sendo possível se estar plenamente satisfeito, pois sempre surgirá uma necessidade que organizará e dirigirá novas condutas motivacionais.

Partindo de um outro prisma, Locke (apud Bergamine \& Coda, 1990 p.66) afirma que "a satisfação no trabalho é um estado de prazer emocional resultante da avaliação que um profissional faz sobre até que ponto o seu trabalho apresenta a capacidade de facilitar ou permitir o atendimento de seus objetivos e valores". E, corroborado por Levy-Leboyer (1994), quando 
afirma que motivação significa a vontade de realizar um trabalho ou alcançar um objetivo, para o qual é necessário fazer e manter um esforço até que o objetivo seja atingido, dedicando a ele toda energia necessária, e por Minicucci (1983), ao afirmar que a motivação é o que leva a pessoa na direção de um objetivo. Assim, de acordo com esses autores, a motivação está sempre relacionada a possibilidade de alcance dos objetivos. Ou seja, à medida que a possibilidade aumenta ou diminui, proporcionalmente ocorre o mesmo com a motivação. Neste sentido, um conceito elaborado por Murray (1971, p.20) consegue sintetizar, de certas forma, a questão do objetivo e sua influência para a motivação quando afirma que “... há acordo geral em que um motivo é um fator interno que dá início, dirige e integra o comportamento de uma pessoa". Para ele, por um lado, um motivo divide-se em duas partes: impulso e objetivo. Impulso é um processo interno que incita uma pessoa à ação, e pode ser influenciado pelo ambiente externo (por exemplo, temperatura), mas é interno. Por outro, o objetivo apresenta um certo efeito redutor ou saciante sobre o incitamento interno. Um objetivo ou recompensa poderá envolver um objetivo externo, como o alimento, mas o processo de cessação do impulso é, em si mesmo, interno. Em consonância com esta opinião Gooch \& Mcdowel (1988) afirmam que uma pessoa não motiva a outra, apenas se estimula em uma determinada direção, porém para seguir essa direção é necessário que a mesma esteja ligada a um desejo.

É importante salientar que os conceitos, mesmo sendo genéricos, não desprezam a especificidade de cada ser humano. No estudo da motivação e satisfação deve-se levar em consideração os aspectos de diferenças individuais e culturais quando da escolha da ação que direciona o comportamento até a satisfação. $\mathrm{Na}$ opinião de Davis \& Newstrom (1992, p. 47) "cada indivíduo tem tendência a desenvolver certas forças motivacionais como produto do ambiente cultural no qual vive, afetando a maneira pela qual as pessoas percebem seu trabalho e encaram suas vidas".

A partir destes e de outros conceitos sobre o que é, como ocorre, e o que não é motivação e satisfação, várias teorias foram elaboradas visando explicar como proporcionar satisfação ao homem em seu ambiente de trabalho. Uma das teorias, elaborada por Abraham Maslow (apud Silva Júnior, 1998), parte do pressuposto que existe uma hierarquia nas necessidades humanas. Nesta, são apresentadas três tipos de necessidades: as biológicas, que uma vez satisfeitas abrem espaços para as necessidades sociais, as quais satisfeitas, dão lugar as verdadeiras necessidades psicológicas. Seqüencialmente as necessidades estão dispostas da seguinte forma: necessidades fisiológicas, necessidades de segurança, necessidades sociais, necessidades de estima e necessidades de auto-realização. Entretanto, é importante salientar que nem sempre essa hierarquia é rigorosamente seguida. Outras teorias apontam a questão da satisfação como algo que surge mediante comparações feitas pelos funcionários, é o caso do modelo da eqüidade de J. Stacy Adams (apud Silva, 2000). Segundo ele, a satisfação dos funcionários é fruto da justiça percebida por estes, quando fazem comparações entre os esforços demandados no trabalho (educação, tempo de casa, desempenho) e as recompensas recebidas (pagamento real, benefícios, e recompensas psicológicas e sociais), ao mesmo tempo que fazem comparações com outras pessoas que servem como referências. Neste modelo o sistema de recompensa engloba os níveis social, econômico e psicológico. Uma outra teoria bastante aceita, é a teoria dos dois fatores de Frederick Herzberg.(1968). As variáveis que compõem cada fator são apresentadas de forma clara e direta o que, aliado ao fato de a mesma estar ligada especificamente a análise da satisfação no trabalho, a coloca como a principal referência deste estudo.

$\mathrm{Na}$ década de 50, Herzberg desenvolveu uma pesquisa com engenheiros e contadores de vários países (inclusive comunistas) que tinha por objetivo identificar o que motivava os trabalhadores. Além das categorias, ele também desenvolveu a investigação junto a supervisores de nível inferior, profissionais liberais do sexo feminino, administradores agrícolas, funcionários de manutenção de hospitais, supervisores industriais e enfermeiras entre outros. A pergunta básica feita por Herzberg para estas pessoas foi "Que ocorrências no trabalho lhes haviam proporcionado extrema satisfação ou extrema insatisfação" (p.8). Também pediu que descrevessem as condições que as levaram a esse sentimento. $\mathrm{O}$ que se descobriu a partir dai foi que os fatores que geram satisfação (e motivação) no trabalho são independentes e distintos dos fatores que conduzem à insatisfação no trabalho. Diante disso, afirma que o oposto de satisfação no trabalho não é insatisfação, mas sim nenhuma satisfação no trabalho. Da mesma forma, o oposto de insatisfação no trabalho não é satisfação, mas nenhuma insatisfação no trabalho.

Foi baseado nesta pesquisa que Herzberg elaborou a denominada teoria dos dois fatores. Para o autor a ausência de determinados fatores de trabalho pode acarretar insatisfação; entretanto, a sua presença não causaria satisfação, mas evitaria a insatisfação. Por um lado, esses são os fatores higiênicos, que estão ligados ao contexto do trabalho. Por outro, as boas condições de trabalho, geradas pela presença dos fatores higiênicos, já são os primeiros passos em direção à 
satisfação. O passo seguinte, e não menos importante, é pôr em prática os fatores que irão proporcionar aos trabalhadores um sentimento de satisfação, sendo conhecidos como fatores de motivação, estando geralmente ligados ao conteúdo do trabalho.

Quando os fatores de higiene são otimizados, evitam insatisfação. Entretanto, quando existe uma otimização dos fatores de motivação, geralmente provocam satisfação. São considerados como fatores higiênicos as políticas organizacionais e de administração, a supervisão, o relacionamento, as condições de trabalho, o salário, a segurança no cargo e o status. Já os fatores de motivação estão relacionados à responsabilidade, à possibilidade de crescimento, à liberdade de decisão, ao conteúdo do cargo, à realização, ao reconhecimento, ao uso pleno das habilidades pessoais e ao estabelecimentos de objetivos e avaliações relacionada com eles. Em uma leitura psicológica os fatores higiênicos podem ser denominados de extrínsecos, enquanto os fatores de motivação de intrínsecos.

\section{Método}

Este estudo teve por finalidade verificar se os funcionários dos hotéis de João Pessoa - Pb, estavam satisfeitos no trabalho. Para tal, entendeu-se ser o método exploratório, do tipo exploratório-descritivo combinado, o mais adequado para a condução deste. Como parte complementar ao método, e objetivando um maior conhecimento do assunto em questão, foram implementados outros procedimentos, principalmente, levantamentos de dados em fontes secundárias como: nos próprios hotéis, departamento de turismo do Estado e do Município, associação dos proprietários de hotéis, sindicato dos funcionários de hotéis, publicações e conversas informais com pessoas que atuam no setor.

\section{Sujeitos}

Esta pesquisa foi realizada em 14 hotéis de João Pessoa, e sua população alvo foram os 456 funcionários distribuídos entre os cargos pesquisados nestes, a partir da qual foi composta uma amostra com 69 componentes, dividida entre dois estratos de acordo com a localização do hotel (centro ou praia). No geral a pesquisa revelou que os funcionários são em sua maioria do sexo masculino, jovens e com menos de um ano no emprego. Outro dado importante a se considerar é o nível de escolaridade, e existindo uma razoável distribuição dos respondentes. Entretanto, deve-se observar que 43,5\% dos sujeitos têm no máximo o primeiro grau completo.

\section{Instrumentos}

Com o objetivo de coletar os dados para este trabalho, foi utilizado um questionário, do tipo estruturado não disfarçado. Este, foi composto por 31 questões e dividido em duas partes: na primeira as perguntas eram relacionadas a dados demográficos como cargo, idade, tempo de serviço, sexo, estado civil e nível de escolaridade; na segunda parte, foram apresentadas várias questões sobre as variáveis Trabalho (treinamento, carga de trabalho, turno de trabalho, reconhecimento, trabalho interessante, relação trabalho/habilidades e conhecimentos, relação tarefa/função, relação tarefas/ aptidões.); Relacionamento (relacionamento com colegas, relacionamento com superiores, interesse da empresa pelo relacionamento, investimento da empresa em relacionamento, influência do relacionamento no trabalho); Salário (relação salário/atividades, relação salários prêmios e benefícios/atividades desempenhadas, comparação salário recebido/salário pago por outros hotéis, influência da remuneração no desempenho, relação remuneração/condições da empresa, relação estabilidade do funcionário/remuneração); Autonomia (liberdade de decisão no trabalho, relação responsabilidade/autonomia e supervisão); Perspectiva (desenvolvimento profissional, desenvolvimento pessoal, promoção e apoio ao estudo). Para cada pergunta o respondente encontrava duas opções: uma afirmativa (indicativa de satisfação) e outra negativa (indicativa de insatisfação).

\section{Procedimentos}

Mesmo considerando como universo os hotéis de João Pessoa, decidiu-se por pesquisar os 14 hotéis com capacidade a partir de 70 leitos. Isto porque os hotéis com um número inferior de leitos, em sua maioria, não dispunham dos cargos pesquisados por este trabalho (frente de hotel, recepção, telefonia, limpeza higiene e conservação, lavanderia, restaurante, café da manhã, camaria e lazer e recreação). Para efeito de distribuição da população em amostras e, pautando-se as diferenças existentes (localização, porte, serviços e clientela) entre os hotéis, optou-se pelo processo de amostragem aleatória estratificada proporcional. Sendo assim, foram considerados dois estratos: o estrato 1, composto pelos hotéis situados na região da praia, com uma população de 380 funcionários; e o estrato 2, composto pelos hotéis localizados no centro da cidade, com uma população de 76 funcionários.

No processo de definição das amostras, foi preciso considerar as dificuldades existentes para a coleta dos dados. Decidiu-se, então, por tomar uma amostra representativa de $15 \%$ dos funcionários, que correspondem a 69 componentes, distribuídos entre os cargos de interesse deste trabalho. Após o processamento das informações, considerando-se um nível de confiança de $90 \%$, obteve-se uma margem de erro de estimativa de $5,6 \%$ a $9,8 \%$ para inferência sobre a proporção de

Psico-USF, v.6, n.1, p.47-57, jan./jun. 2001 
sucesso $p$, correspondente aos itens do questionário aplicado na amostra de funcionários. Definido o tamanho das amostras, observou-se o número de funcionários por cargo/função na população e determinou-se o critério da proporcionalidade.
No momento da entrega do questionário ao funcionário, era explicado o objetivo da pesquisa, o caráter sigiloso das informações prestadas, bem como, que sua participação era voluntária. Posteriormente os respondentes devolviam o questionário em uma data combinada.

Tabela 1. Perfil dos funcionários dos hotéis de João Pessoa

\begin{tabular}{|c|c|c|c|}
\hline Variáveis & Variáveis & $\begin{array}{c}\text { Freqüência } \\
f\end{array}$ & $\begin{array}{c}\text { Percentual } \\
\%\end{array}$ \\
\hline \multirow[t]{4}{*}{ Sexo } & Masculino & 39 & 56,5 \\
\hline & Feminino & 30 & 43,5 \\
\hline & Total & 69 & 100,0 \\
\hline & $18 a<26$ & 24 & 34,8 \\
\hline \multirow[t]{5}{*}{ Faixa etária } & $26 a<34$ & 22 & 31,9 \\
\hline & $34 \mathrm{a}<42$ & 17 & 24,6 \\
\hline & a partir de 42 & 6 & 8.6 \\
\hline & Total - & 69 & 100,0 \\
\hline & $<$ de 1 ano & 36 & 52,2 \\
\hline \multirow[t]{5}{*}{ Tempo de serviço } & $1 \mathrm{a}<4$ anos & 19 & 27,5 \\
\hline & $4 \mathrm{a}<7$ anos & 9 & 13,0 \\
\hline & a partir de 7 anos & 5 & 7.1 \\
\hline & Total & 69 & 100,0 \\
\hline & Solteiro & 35 & 50,7 \\
\hline \multirow[t]{3}{*}{ Estado civil } & Casado & 26 & 37,7 \\
\hline & Outros & 8 & 11.5 \\
\hline & Total & 69 & 100,0 \\
\hline Nível de & Analfabeto & 1 & 1,4 \\
\hline \multirow[t]{7}{*}{ Escolaridade } & $1^{\circ} \mathrm{Grau}$ Incompleto & 17 & 24,6 \\
\hline & $1^{\circ}$ Grau Completo & 12 & 17,4 \\
\hline & $2^{\circ}$ Grau Incompleto & 11 & 15,9 \\
\hline & $2^{\circ}$ Grau Completo & 19 & 27,5 \\
\hline & Superior Incompleto & 8 & 11,6 \\
\hline & Superior Completo & 1 & 1,4 \\
\hline & Total & 69 & 100,0 \\
\hline
\end{tabular}




\section{Resultados}

Análise das respostas dadas pelos funcionários às variáveis independentes

De um modo geral, os funcionários dos hotéis de João Pessoa em sua maioria concordaram com a opção A, evidenciando, assim, uma satisfação destes com o seu trabalho. Entre as cinco variáveis pesquisadas, em três as respostas na opção A foram predominantes, e em duas predominaram a opção B. Trabalho, relacionamento e perspectiva foram as variáveis indicativas de satisfação (opção A), sendo que, dentre estas, trabalho, foi a variável que apresentou maior incidência de satisfação. Autonomia e salário, foram as variáveis indicativas de insatisfação (opção B), cabendo à variável salário o maior índice de insatisfação (ver tabela 2). A seguir, será feita uma análise pormenorizada das variáveis e dos seus componentes.

Tabela 2. Respostas dadas pelos funcionários dos hotéis de João Pessoa às variáveis independentes

\begin{tabular}{lccc}
\hline Variáveis & Alternativas & Freqüência $\boldsymbol{F}$ & Percentual \% \\
\hline Trabalho & Resposta A & 390 & 72,1 \\
& Resposta B & 151 & 27,9 \\
Relacionamento & Resposta A & 210 & 63,0 \\
& Resposta B & 123 & 37,0 \\
Salário & Resposta A & 159 & 40,4 \\
& Resposta B & 234 & 59,6 \\
Perspectiva & Resposta A & 155 & 59,6 \\
& Resposta B & 105 & 40,4 \\
Autonomia & Resposta A & 93 & 47,0 \\
& Resposta B & 105 & 53,0 \\
Total & Resposta A & 1007 & 58,4 \\
& Resposta B & 718 & 41,6
\end{tabular}

Resposta A - Indicativo de Satisfação

Resposta B- Indicativo de Insatisfação

\section{Trabalho}

O objetivo da variável é verificar se o hotel oferece as condições necessárias para realização das tarefas e satisfação dos funcionários dos hotéis de uma forma geral. Esta tem oito componentes através dos quais foi estudada, sendo que, em seis a incidência de satisfação foi predominante, enquanto em dois predominou a insatisfação. Turno de trabalho foi o componente que mais contribuiu para a satisfação, enquanto treinamento foi quem mais contribuiu para a insatisfação. 
Tabela 3. Respostas dadas pelos funcionários dos hotéis de João Pessoa aos componentes da variável trabalho

\begin{tabular}{|c|c|c|c|}
\hline Componentes & Alternativas & $\begin{array}{c}\text { Freqüência } \\
\qquad F\end{array}$ & $\begin{array}{c}\text { Percentual } \\
\%\end{array}$ \\
\hline Treinamento & Resposta A & 31 & 47,0 \\
\hline & Resposta B & 35 & 53,0 \\
\hline Carga de Trabalho & Resposta A & 54 & 79,4 \\
\hline & Resposta B & 14 & 20,6 \\
\hline Turno de Trabalho & Resposta A & 63 & 91,3 \\
\hline & Resposta B & 6 & 8,7 \\
\hline Reconhecimento & Resposta A & 33 & 49,3 \\
\hline & Resposta B & 34 & 50,7 \\
\hline Trabalho Interessante & Resposta A & 61 & 88,4 \\
\hline & Resposta B & 8 & 11,6 \\
\hline Trabalho/ Habilidades e & Resposta A & 56 & 83,6 \\
\hline Conhecimentos & Resposta B & 11 & 16,4 \\
\hline Tarefa x Função & Resposta A & 40 & 58,0 \\
\hline & Resposta B & 29 & 42,0 \\
\hline Atividade x Aptidão & Resposta A & 52 & 78,5 \\
\hline & Resposta B & 14 & 21,5 \\
\hline Total & Resposta A & 390 & 72,1 \\
\hline & Resposta B & 151 & 27,9 \\
\hline
\end{tabular}

Resposta A - Indicativo de Satisfação

Resposta B- Indicativo de Insatisfação

Conforme mostra a Tabela 3, a maioria das respostas indicam que não há excessos na carga de trabalho, que o turno de trabalho é satisfatório, desenvolvem um trabalho interessante e que requer habilidades e conhecimentos, não desenvolvem tarefas além de suas funções e trabalham em consonância com as suas aptidões. Entretanto, sentem carência de treinamento e de reconhecimento por parte do hotel. 


\section{Relacionamento}

Tabela 4. Respostas dadas pelos funcionários dos hotéis de João Pessoa aos componentes da variável relacionamento

\begin{tabular}{|c|c|c|c|}
\hline Componentes & Alternativas & $\begin{array}{l}\text { Freqüência } \\
\qquad F\end{array}$ & $\begin{array}{l}\text { Percentual } \\
\quad \%\end{array}$ \\
\hline Relacionamento com Colegas & $\begin{array}{l}\text { Resposta A } \\
\text { Resposta B }\end{array}$ & $\begin{array}{c}63 \\
6\end{array}$ & $\begin{array}{c}91,3 \\
8,7\end{array}$ \\
\hline $\begin{array}{l}\text { Relacionamento } \\
\text { Superiores }\end{array}$ & $\begin{array}{l}\text { Resposta A } \\
\text { Resposta B }\end{array}$ & $\begin{array}{l}52 \\
16\end{array}$ & $\begin{array}{l}76,5 \\
23,5\end{array}$ \\
\hline $\begin{array}{l}\text { Interesse do Hotel em } \\
\text { Relacionamento }\end{array}$ & $\begin{array}{l}\text { Resposta A } \\
\text { Resposta B }\end{array}$ & $\begin{array}{l}24 \\
40\end{array}$ & $\begin{array}{l}37,5 \\
62,5\end{array}$ \\
\hline $\begin{array}{l}\text { Investimento do Hotel em } \\
\text { Relacionamento }\end{array}$ & $\begin{array}{l}\text { Resposta A } \\
\text { Resposta B }\end{array}$ & $\begin{array}{l}20 \\
46\end{array}$ & $\begin{array}{l}30,3 \\
69,7\end{array}$ \\
\hline $\begin{array}{l}\text { Influência do Relacionamento } \\
\text { nos Resultados }\end{array}$ & $\begin{array}{l}\text { Resposta A } \\
\text { Resposta B }\end{array}$ & $\begin{array}{l}51 \\
15\end{array}$ & $\begin{array}{l}77,3 \\
22,7\end{array}$ \\
\hline Total & $\begin{array}{l}\text { Resposta A } \\
\text { Resposta B }\end{array}$ & $\begin{array}{l}210 \\
123\end{array}$ & $\begin{array}{l}63,0 \\
37,0\end{array}$ \\
\hline
\end{tabular}

Resposta A - Indicativo de Satisfação

Resposta B- Indicativo de Insatisfação

De acordo com a Tabela 4, dos cinco componentes desta variável, três contribuíram para a satisfação e dois, para a insatisfação. Relacionamento com colegas foi o componente que mais contribuiu para a satisfação, enquanto investimento do hotel em relacionamento foi que mais contribuiu para a insatisfação. Considerando-se os dados obtidos, pode-se afirmar que o relacionamento com colegas e superiores é satisfatório, e a maneira como se relacionam no hotel tem uma influência positiva no resultado do trabalho. No entanto, os hotéis não se interessam pelo relacionamento entre os funcionários $\mathrm{e}$, como conseqüência, também não investem na melhoria deste relacionamento.

\section{Salário}

De acordo com a Tabela 5 , nesta variável a incidência da insatisfação foi predominante. Entre os seis componentes pesquisados cinco influenciaram a insatisfação e um, a satisfação. O que mais contribuiu para a insatisfação foi o componente que diz respeito à relação entre o salário e as atividades desempenhadas, e o único em que predominou a satisfação foi influência da remuneração no desempenho. A análise desta variável aponta para a incompatibilidade entre salário e atividades desempenhadas, até mesmo quando acrescido de comissões e benefícios; o salário continua baixo quando comparado aos que são pagos por outros hotéis, e não contribui para a permanência dos funcionários no hotel. Mas, segundo a maioria, estes problemas não prejudicam o desempenho. 
Tabela 5. Respostas dadas pelos funcionários dos hotéis de João Pessoa aos componentes da variável salário

\begin{tabular}{|c|c|c|c|}
\hline Componentes & Alternativas & $\begin{array}{c}\text { Freqüência } \\
f f\end{array}$ & $\begin{array}{c}\text { Percentual } \\
\%\end{array}$ \\
\hline \multirow[t]{2}{*}{ Compatibilidade com as Atividades } & Resposta A & 20 & 29,4 \\
\hline & Resposta B & 48 & 70,6 \\
\hline Compatíveis com & Resposta A & 20 & 30,8 \\
\hline Atividades & Resposta B & 45 & 69,2 \\
\hline \multirow[t]{2}{*}{ Comparação com Outros Hotéis } & Resposta A & 31 & 47,0 \\
\hline & Resposta B & 35 & 53,0 \\
\hline \multirow[t]{2}{*}{ Salário x Condições do Hotel } & Resposta A & 22 & 32,8 \\
\hline & Resposta B & 45 & 67,2 \\
\hline \multirow{2}{*}{$\begin{array}{l}\text { Salário x Influência no } \\
\text { Desempenho }\end{array}$} & Resposta A & 48 & 69,6 \\
\hline & Resposta B & 21 & 30,4 \\
\hline \multirow[t]{2}{*}{ Salário x Permanência do Funcionário } & Resposta A & 18 & 31,0 \\
\hline & Resposta B & 40 & 69,0 \\
\hline \multirow[t]{2}{*}{ Total } & Resposta A & 159 & 40,4 \\
\hline & Resposta B & 234 & 59,6 \\
\hline
\end{tabular}

Resposta A - Indicativo de Satisfação

Resposta B- Indicativo de Insatisfação

Perspectiva

Tabela 6. Respostas dadas pelos funcionários dos hotéis de João Pessoa aos componentes da variável perspectiva

\begin{tabular}{lccc}
\hline Componentes & Alternativas & $\begin{array}{c}\text { Freqüência } \\
\boldsymbol{f}\end{array}$ & $\begin{array}{c}\text { Percentual } \\
\mathbf{\%}\end{array}$ \\
\hline $\begin{array}{l}\text { Desenvolvimento } \\
\text { Profissional }\end{array}$ & Resposta A & 40 & 61,5 \\
Desenvolvimento Pessoal & 25 & 38,5 \\
& Resposta B & 37 & 57,8 \\
\multirow{2}{*}{ Promoção x Desempenho } & Resposta A & 27 & 42,2 \\
& Resposta B & 39 & 58,2 \\
Apoio ao Estudo & Resposta A & 28 & 41,8 \\
& Resposta B & & 60,9 \\
Total & & 39 & 39,1 \\
& Resposta A & 25 & 59,6 \\
\hline
\end{tabular}

Resposta A - Indicativo de Satisfação

Resposta B- Indicativo de Insatisfação

Como se percebe na Tabela 6 , as respostas indicativas da satisfação predominaram nesta variável em todos os componentes. Desenvolvimento profissional foi o componente que mais contribuiu para a satisfação e desenvolvimento pessoal foi o que menos contribuiu. Segundo os respondentes, os hotéis permitem um desenvolvimento profissional e pessoal, promovem baseados no desempenho e apoiam o funcionário que pretende estudar.

Autonomia

Nesta variável, de acordo com o que mostra a Tabela 7, houve uma incidência maior de respostas tendentes a insatisfação. Dos três componentes, dois 
influenciaram a insatisfação e um, a satisfação. O maior índice de insatisfação foi no componente liberdade de decisão no trabalho, e o único em que prevaleceu a satisfação foi em responsabilidade $\mathrm{x}$ autonomia. As respostas mostram que os funcionários não têm liberdade para tomar decisões inerentes ao trabalho, têm bastante responsabilidade e autonomia e trabalham supervisionados por várias pessoas.

Tabela 7. Respostas dadas pelos funcionários dos hotéis de João Pessoa aos componentes da variável autonomia

\begin{tabular}{|c|c|c|c|c|}
\hline Componentes & & Alternativas & $\begin{array}{c}\text { Freqüência } \\
f\end{array}$ & $\begin{array}{c}\text { Percentual } \\
\%\end{array}$ \\
\hline Liberdade de & & Resposta A & 24 & 36,4 \\
\hline Decisão & & Resposta B & 42 & 63,6 \\
\hline Responsabilidade & $\mathbf{x}$ & Resposta A & 40 & 60,6 \\
\hline Autonomia & & Resposta B & 26 & 39,4 \\
\hline \multirow[t]{2}{*}{ Supervisão } & & Resposta A & 29 & 43,9 \\
\hline & & Resposta B & 37 & 56,1 \\
\hline \multirow[t]{2}{*}{ Total } & & Resposta A & 93 & 47,0 \\
\hline & & Resposta B & 105 & 53,0 \\
\hline
\end{tabular}

Resposta A - Indicativo de Satisfação

Resposta B- Indicativo de Insatisfação

Após a análise dos dados de cada variável, foram cruzadas as respostas dadas nos estratos 1 (hotéis da praia) e 2 (hotéis do centro), com a finalidade de verificar a existência de diferença significativa quanto à satisfação / insatisfação dos funcionários em ambos os estratos. O teste estatístico utilizado para tal efeito foi o "qui-quadrado", no nível de significância de 5\%.

Este cruzamento mostrou que apenas em dois componentes na variável trabalho, e um nas variáveis relacionamento, salário e perspectiva ocorreram diferenças significativas no tocante à satisfação / insatisfação dos funcionários nos dois estratos, o que indica que, na maioria dos componentes das variáveis pesquisadas, o nível de satisfação ou insatisfação, independentemente dos estratos, não difere significativamente (ver quadro 1).

Quadro 1. Teste de qui-quadrado para as respostas dadas pelos funcionários dos hotéis nos estratos 1 e 2 às variáveis independentes.

\begin{tabular}{|l|c|c|c|}
\hline Variáveis Independentes & Questões & $\begin{array}{c}\text { Estatística } \\
x^{2}\end{array}$ & $\begin{array}{c}\text { Significância } \\
p\end{array}$ \\
\hline Trabalho & Q 1 & 4,39189 & 0,03611 \\
& Q 2 & 6,20325 & 0,01275 \\
\hline Relacionamento & Q 9 & 5,68820 & 0,04725 \\
\hline Salário & Q 16 & 7,60369 & 0,00582 \\
\hline Perspectiva & Q 20 & 6,56839 & 0,01645 \\
\hline Autonomia & -- & -- & não houve \\
\hline
\end{tabular}

$\mathrm{Na}$ variável trabalho duas questões apresentaram diferenças significativas. $\mathrm{Na}$ questão 1, foi perguntado aos funcionários se os hotéis ofereciam, ou não, o treinamento necessário para o desempenho da função; e na questão 2, perguntou-se se a carga de trabalho era, ou não-compatível com o expediente. Nestas o teste mostrou que no nível de significância de 5\%, há diferença significativa nas respostas dos funcionários. Tanto na questão 1 como na 2 , nos hotéis da praia (estrato 1) houve uma predominância de respostas na opção A, e nos hotéis do centro (estrato 2 ), quanto à questão 1 predominaram as respostas na opção B e, em relação à questão 2, as respostas foram literalmente divididas. Ou seja, nos hotéis da praia os funcionários estão satisfeitos com o treinamento e a carga de trabalho, e nos hotéis do centro estão insatisfeitos no tocante ao treinamento e divididos quanto à carga de trabalho ser ou não compatível com o expediente.

Quanto à variável relacionamento, apenas na questão 9 verificou-se a existência de diferença 
significativa. Nesta se indagou aos funcionários se eles tinham ou não um bom relacionamento com os colegas de trabalho. Neste caso, também se verifica que, ao nível de significância de 5\%, há diferença significativa entre o que pensam os funcionários do estrato 1 e os funcionários do estrato 2 . No estrato 1 , a tendência revelada foi próxima da unanimidade quanto à satisfação no relacionamento com os colegas de trabalho; já no estrato 2 , pouco mais da metade dos respondentes consideraram-se satisfeitos com $\mathrm{O}$ relacionamento com os colegas de trabalho.

$\mathrm{Na}$ questão 16 (salário), perguntou-se aos respondentes se, em caso de comparação com outros hotéis, estes se consideravam bem ou mal remunerados. Percebe-se, com base na tabela acima, que há diferença nas respostas dos funcionários do estrato 1 e do estrato 2, no nível de significância de 5\%. Segundo os respondentes do estrato 1 (hotéis da praia), são bem remunerados se comparados ao que pagam outros hotéis; já para os respondentes do estrato 2 (hotéis do centro), são mal remunerados se comparado ao que pagam os outros hotéis.

$\mathrm{Na}$ variável perspectiva, quando indagados sobre a possibilidade de desenvolvimento profissional no hotel (questão 20), os respondentes dos hotéis da praia afirmaram predominantemente que sim, ao contrário dos respondentes dos hotéis do centro. A aplicação do teste já mencionado, indicou que há diferença significativa, ao nível de significância de 5\%, entre as respostas dos funcionários de ambos os estratos, ou seja, no estrato 1 os funcionários responderam que há possibilidade de desenvolvimento profissional, enquanto no estrato 2 responderam que não.

$\mathrm{Na}$ variável autonomia, não se verificou a existência de diferença significativa entre as respostas dos funcionários nos referidos estratos.

\section{Conclusão}

Quanto ao perfil dos funcionários, um dos dados mais importantes a se considerar é a alta taxa de "turnover" existente nos hotéis, onde mais da metade dos sujeitos estavam no emprego a menos de um ano. Esse dado sucinta duas possibilidades: a primeira relaciona-se ao fato da empresa está investindo em todo o processo de recrutamento/seleção/treinamento, arcando com os custos que o envolve, e posteriormente por não ter uma boa política de manutenção de Recursos Humanos, estes deixam a organização em busca de melhores oportunidades; na segunda, o hotel contrata mão-de-obra barata, com baixa escolaridade, e pouca qualificação, oferece um treinamento insuficiente, e exige destes um nível de qualidade que os mesmos não conseguem apresentar, sendo por esse motivo demitidos, iniciando-se um novo ciclo. Estas hipóteses são fortalecidas à medida que os funcionários revelaram não sentirem-se reconhecidos e não disporem de treinamento suficiente para o bom desempenho das funções.

Quando da análise da variável relacionamento percebe-se, mesmo predominando nesta um indicativo de satisfação, que os hotéis não se preocupam com o assunto, o que fica evidenciado com a inexistência de programas de melhoria de relacionamento interpessoal. Assim, quando da ocorrência de alguma situação problema a empresa tenta resolver do modo tradicional: mediante uma reunião com as partes interessadas. Entretanto, apenas para $37 \%$ o relacionamento é insatisfatório. Porém, esse ainda é um índice elevado quando se pretende ter um clima de harmonia e cooperação.

Em relação ao salário, este apresenta-se como indicativo de insatisfação. O único componente onde predominaram as respostas indicativas de satisfação foi no tocante a influência do salário no desempenho. Neste, os funcionários afirmaram que o fato de não ser bem remunerados não influencia no desempenho. Entretanto, se esta afirmativa for confrontada com a realidade, observar-se-á claramente que esta é apenas a vontade expressa do respondente, com base em seu código de normas e valores. $\mathrm{Na}$ verdade, quando se é mal remunerado existe uma tendência a relaxar no desenvolvimento das tarefas, embora, o fato de ser bem remunerado, por si só, não leva ninguém a otimizar o desempenho.

O cruzamento das respostas dadas pelos funcionários dos hotéis da praia com os do centro, evidenciou não haver diferenças significativas na maioria das questões. Entretanto, algumas das respostas mostram claramente as diferenças existentes entre os dois grupos de hotéis. Enquanto na região da praia os hotéis oferecem mais treinamentos, salários melhores quando comparados aos demais, e não há sobrecarga de trabalho, nos hotéis do centro da cidade ocorre o contrário. Esse fato, pode ser conseqüência de uma maior profissionalização e qualificação da administração dos hotéis praianos, o que resulta em uma melhor política de Recursos Humanos se comparados aos hotéis do centro da cidade, onde geralmente, prevalece um modelo de administração que não leva em consideração a necessidade de contratação de mão-deobra qualificada nem de treinamento, pois a visão predominante é que isso representa custo e não investimento na qualidade dos serviços e na satisfação dos clientes e dos funcionários.

À luz da teoria dos dois fatores, de Frederick Herzberg, pode-se afirmar que dentre os 26 compo- 
nentes que integram as variáveis estudadas, 16 são fatores higiênicos e 10 são fatores de motivação. Avaliando-se as respostas dadas pelos funcionários dos hotéis de João Pessoa, percebe-se a presença de 7 fatores higiênicos (turno de trabalho, carga de trabalho, relação tarefa/ função, relacionamento com colegas, relacionamento com superiores, influência do relacionamento no trabalho, influência do salário no desempenho), e a presença de 8 fatores de motivação no trabalho (relação trabalho/habilidades e conhecimentos, trabalho interessante, relação tarefas/aptidões, desenvolvimento profissional, desenvolvimento pessoal, promoção, apoio ao estudo e a relação responsabilidade/autonomia). Partindo-se dos referidos pressupostos teóricos, pode-se concluir que no conjunto dos hotéis de João Pessoa considerando-se a forte presença dos fatores higiênicos, e principalmente de motivação, que os funcionários estão satisfeitos com o trabalho.

\section{Referências Bibliográficas}

Archer, Earnest R. (1990). O mito da motivação. Em Bergamine, C. W. \& Coda, R. (org), Psicodinâmica da vida organizacional. São Paulo: Pioneira.

Bergamine, C. R. (1990). Motivação: mitos, crenças e malentendidos. Em Bergamine, C. R. \& Coda, R. (0rg), Psiocodinâmica da vida organizacional. São Paulo:Pioneira.
Bergamine, C. W. \& Coda, R. (org.). (1990). Psicodinâmica da vida organizacional. São Paulo: Pioneira.

David, Keith \& Newstrom, Jones W. (1992). Comportamento bumano no trabalho. São Paulo: Pioneira.

Gooch, B. G. \& Mcdowell, B. J. (1988). "Use of anxiety to motivate". Perssonnel Journal, april.

Herzberg, Frederick. (1968). Novamente como se faz para motivar funcionários. Biblioteca Havard de Administração de Empresas, 1 (13): 1-13

Levy-Leboyer C. (1994). A crise das motivaçooes, 3 ed. São Paulo: Atlas.

Minicucci, Agostinho. (1983). Psicologia aplicada à administração, 3 ed. São Paulo: Atlas.

Murray, E. (1971). Motivação e emoção. Rio de Janeiro: Zahar.

Silva Júnior, N. A. (1998). Qualidade dos servicos prestados pelos hotéis de João Pessoa: uma perspectiva dos hóspedes e dos funcionários. Dissertação de Mestrado, Universidade Federal de Alagoas, Maceió.

Silva, Walmir Rufino. (2000). Motivação no trabalho. João Pessoa: Editora Universitária / UFPB.

Skinner, B. F. (1972). O mito da liberdade. Rio de Janeiro: Bloch Editores.

Sobre o autor

Nelson Aleixo da Silva Júnior é Psicólogo Organizacional, Mestre em Administração pela UFAL, foi instrutor do SENAC entre 1994 e 1998, é Professor da UEPB e membro da direção da ABEP. 